\title{
PROPOSTA DE IMPLEMENTAÇÃO E DESENVOLVIMENTO DOS PROCESSOS DE TECNOLOGIA E INFORMAÇÃO (TI) PARA MELHORIA E MODERNIZAÇÃO DE EQUIPAMENTO TECNOLÓGICOS PARA SUPORTE E PRODUTIVIDADE ORGANIZACIONAL: ESTUDO DE CASO NA EMPRESA X
}

\section{ARTIGO ORIGINAL}

SOARES, Bárbara de Cassia¹, RAMIRES, Julianna da Silva² ${ }^{2}$ ALMEIDA, Victor da Silva $^{3}$, LEITE, Ygor Geann dos Santos ${ }^{4}$, ROBERTO, José Carlos Alves ${ }^{5}$

SOARES, Bárbara de Cassia. Et al. Proposta de implementação e desenvolvimento dos processos de Tecnologia e Informação (TI) para melhoria e modernização de equipamento tecnológicos para suporte e produtividade organizacional: estudo de caso na empresa X. Revista Científica Multidisciplinar Núcleo do Conhecimento. Ano. 06, Ed. 11, Vol. 14, pp. 191-212. Novembro de 2021. ISSN: 2448-0959, Link de acesso: https://www.nucleodoconhecimento.com.br/administracao/desenvolvimento-dosprocessos, DOI: 10.32749/nucleodoconhecimento.com.br/administracao/desenvolvimento-dosprocessos

\footnotetext{
${ }^{1}$ Graduando do curso de Administração.

${ }^{2}$ Graduando do curso de Administração.

${ }^{3}$ Coorientador. Mestre em Engenharia de Processos. Pós-Graduando em Neuropsicopedagogia Institucional. Especialista em Gestão Estratégica de RH. Graduado em Administração e Pedagogia.

${ }^{4}$ Coorientador. Mestre em Ciência e Engenharia de Materiais. Especialista em Engenharia da Qualidade e Seis Sigma. Graduado em Tecnologia em Gestão da Qualidade.

${ }^{5}$ Orientador. Mestrado profissional em Engenharia de produção. Especialização em Gestão em Logística empresarial. Graduação em Administração com Ênfase em Marketing.
}

RC: 102333

Link de acesso:

https://www.nucleodoconhecimento.com.br/administracao/desenvolvimento-dosprocessos 


\section{RESUMO}

O presente artigo tem como finalidade realizar um estudo de caso na Empresa $\mathrm{X}$, uma empresa de grande porte que atua com a venda de roupas. $O$ artigo nasceu a partir de estudos das análises funcionais, no qual se identificou a área de operações da empresa como a mais crítica. Portanto, como forma auxiliar o estudo foi desenvolvida a questão norteadora: como o desenvolvimento dos processos de Tecnologia e Informação (TI) pode auxiliar na modernização de equipamento tecnológicos para suporte e produtividade organizacional? O objetivo geral da pesquisa consistiu em apresentar uma proposta de implementação e desenvolvimento dos processos de Tecnologia e Informação ( $\mathrm{TI}$ ) para melhoria e modernização de equipamento tecnológicos e para suporte e produtividade organizacional. A metodologia empregada no trabalho, quando sua à natureza, é definida como pesquisa básica. Quanto aos meios, é caracterizada como um estudo de caso e uma pesquisa bibliográfica. No que diz respeito aos fins, caracteriza-se como descritiva. Como resultado, elaborou-se por meio do $5 \mathrm{~W} 2 \mathrm{H}$ um pacote de ações interventivas que visam proporcionar aos consumidores comodidade e economia de tempo. Optou-se por desenvolver um mapeamento dos processos de $\mathrm{Tl}$, estruturar um plano de cotação e compras de materiais tecnológicos, categorizar itens tecnológicos para inserção no processo, treinar colaboradores para manusear tecnológicas, implementar novos sistemas de tecnologias e realizar análises com indicadores sobre os itens. Dessa forma, espera-se que com a introdução das ações interventivas a empresa possa aperfeiçoar os seus processos, aumentar a eficiência e obter vantagens competitivas perante o seu mercado.

Palavras-Chave: Tecnologia e informação, Equipamento tecnológicos, produtividade organizacional, Inovação, Competividade.

RC: 102333

Link de acesso:

https://www.nucleodoconhecimento.com.br/administracao/desenvolvimento-dosprocessos 


\section{INTRODUÇÃO}

O presente artigo realizou um estudo de caso na empresa $X$, uma organização fundada em 1948, no Estado de São Paulo, que tem como fundador oficial da marca um empreendedor, que já atuou na área de moda feminina, moda masculina, moda íntima, moda infantil, acessórios e calçados.

O objetivo geral do estudo consistiu em apresentar uma proposta de implementação e desenvolvimento dos processos de Tecnologia e Informação (TI) para melhoria e modernização de equipamento tecnológicos, que tem como fim o suporte e produtividade organizacional. Auxiliado pelos objetivos específicos buscou-se: estruturar um plano para cotação de compras de itens tecnológicos; desenvolver um treinamento para colaboradores com novas tecnologias e propor uma melhoria nos processos de tecnologia e informação para produtividade da empresa.

A metodologia empregada no trabalho, quanto sua, natureza é definida como uma pesquisa básica. Quantos aos meios, é caracterizado como um estudo de caso e uma pesquisa bibliográfica. No que se diz respeito aos fins, caracteriza-se como descritiva. A ferramenta interventiva utilizada foi $05 \mathrm{~W} 2 \mathrm{H}$, com 0 qual foi desenvolvido um plano de fácil execução, mas que pudessem gerar um efeito na produtividade, como a inserção de treinamento e compras materiais tecnológicos, que irão auxiliar os colaboradores a ampliar sua performance e trazer melhor resultados.

Toda empresa enfrenta uma guerra com a concorrência, que usa seus recursos e habilidades para conquistar o mercado e tentar permanecer nele, ou seja, se uma empresa perder mercado, desaparecerá facilmente. Portanto, pode-se afirmar que a ação é fundamental para estratégia competitiva da empresa, e em razão disso elaborou-se a questão norteadora: como o desenvolvimento dos processos de Tecnologia e Informação (TI) pode auxiliar na modernização de equipamento tecnológicos para suporte e produtividade organizacional?

RC: 102333

Link de acesso:

https://www.nucleodoconhecimento.com.br/administracao/desenvolvimento-dosprocessos 
Tendo em vista a grande concorrência do mercado, as empresas devem estar preparadas para adotar estratégias inovadoras. A implantação de novas tecnologias é um processo necessário para otimizar os mais diversos departamentos da empresa, pois fornece dados que afetam diretamente as boas decisões da administração.

Espera-se que com a introdução destas ações interventivas a empresa consiga desenvolver um novo planejamento com base na estrutura do mercado em que atua, de modo a otimizar a sua estratégia competitiva e desenvolver uma fórmula mais ampla para lidar com a concorrência.

\section{FUNDAMENTAÇÃO TEÓRICA}

A fundamentação teórica, ou referencial teórico, é um dos componentes da pesquisa científica que realiza o desenvolvimento da revisão de textos, artigos, livros, dissertação e teses. Também reconhecidamente nomeada de pesquisa bibliográfica, ela engloba a seleção de materiais de leitura relacionados aos temas abordados pela pesquisa e possibilita discussão e diálogo com autores da área, na tentativa de proporcionar melhor entendimento sobre o fenômeno em estudo (ESTRELA, 2018, p. 76).

O embasamento teórico é essencial, pois é com base nele que se norteia a investigação e a interpretação dos dados coletados para a presente pesquisa. Essa etapa é de extrema importância para pesquisa científica e para a conclusão do curso, e se executada de forma adequada tentará dar credibilidade à pesquisa e inseri-la no contexto do campo científico. Portanto, devem ser buscadas fontes confiáveis que forneçam informações de alta qualidade para a pesquisa (ANA; LEMOS, 2018, p. 532).

RC: 102333

Link de acesso:

https://www.nucleodoconhecimento.com.br/administracao/desenvolvimento-dosprocessos 


\subsection{CONCEITO DE TECNOLOGIA DA INFORMAÇÃO (TI)}

A Tecnologia da Informação ( $\mathrm{Tl}$ ) chegou para atender à complexidade e às necessidades de negócios. Tendo em vista as características do ambiente atual de negócios e gestão, as organizações precisam ser cada vez mais adaptáveis, flexíveis e ágeis, e suas estruturas e processos precisam ser permanentemente reavaliados, reorganizados e revitalizados. Diante disso, a tecnologia da informação terá que identificar, descobrir ou desenvolver e implementar tecnologias e sistemas de informação que apoiem a comunicação empresarial e a troca de ideias e experiências.

Segundo Gomes e Ribeiro (2020, p. 89), a Tecnologia da Informação (TI) é caracterizada por ser um conjunto de tecnologias geralmente associadas à informação e telecomunicações, e as empresas usam esses conjuntos de tecnologia para implementar subsistemas de informação e suas operações.

De acordo com Schneider et al. (2016, p. 171), a Tecnologia da Informação (TI) entende-se como foco principal, ou seja, informação, deve passar a fazer parte do nível estratégico da empresa. A informação não deve se limitar à gestão de recursos internos, ela deve ir além dos limites da empresa e ser sistematicamente integrada aos fornecedores e clientes, pois a $\mathrm{Tl}$ apresenta para a empresa um importante fator competitivo.

Salles et al. (2016) ressalta que:

A tecnologia da informação está começando a desempenhar um papel importante na vida diária de indivíduos e organizações. As decisões relacionadas a este conceito definirão como coletar, analisar e classificar os dados para se tornarem informações e, a partir daí, fornecer, acessar, processar e proteger para fins específicos (SALLES et al., 2016, p. 60).

Esses conjuntos de tecnologia podem identificar, planejar e implementar sistemas de informação integrados e a infraestrutura de suporte correspondente a esses sistemas, de forma que a Tecnologia da Informação possa ser aplicada universalmente às atividades da organização, pois a Tecnologia da Informação

RC: 102333

Link de acesso:

https://www.nucleodoconhecimento.com.br/administracao/desenvolvimento-dosprocessos 
contribui para agilidade na produção e distribuição de bens e serviços, criando e mantendo vantagens competitivas, reduzindo custos e otimizando processos.

\subsection{EVOLUÇÃO DA TI}

Nos últimos 40 anos, a $\mathrm{Tl}$ evoluiu de uma ferramenta simples usada por alguns cientistas para se tornar uma parte central da empresa. Desde a década de 1960, ela era considerada uma ferramenta para cientistas, distante da realidade da organização. Na década de 1970, o investimento continuou, a TI invadiu as organizações, mas ainda estava longe da prática organizacional e foi limitada aos centros de processamento de dados. Com a revolução do microcomputador, o uso da tecnologia pelas organizações explodiu, mudando o foco do mundo do mainframe para os computadores pessoais.

Para Siqueira e Crispim (2014, p. 627), "como resultado, o caos custoso, que em certa medida ocorreu no centro de processamento de dados, agora se multiplica pela invasão das inúmeras estações de trabalho da organização, ocupando uma proporção maior". Devido ao desenvolvimento desordenado, existe um sistema descentralizado que atende as necessidades de um determinado departamento sem qualquer integração com os demais departamentos da organização.

Conforme Batista (2017, p. 133), "a evolução do sistema de informação na organização não é o resultado do plano, mas a intrusão do sistema no dia a dia da organização". Quanto à evolução do sistema na organização, ela pode ser dividida em quatro gerações conforme a forma de evolução. Elas são denominadas: formação, proliferação, dispersão e unidade.

No estágio de formação, sistemas isolados são criados nas visões segmentadas de diferentes departamentos e organizações. Com o desenvolvimento da tecnologia e a comodidade do acesso à tecnologia, os sistemas proliferaram, resultando na divisão de ilhas, em que cada sistema é concebido isoladamente para realizar tarefas específicas. A etapa de descentralização unifica o sistema departamental e o separa

RC: 102333

Link de acesso:

https://www.nucleodoconhecimento.com.br/administracao/desenvolvimento-dosprocessos 
ainda mais da organização. Na fase de integração, o período atual, as organizações estão tentando ajustar seus parques tecnológicos para que possam reproduzir fielmente as preocupações organizacionais.

\subsection{GESTÃO DA INOVAÇÃO}

Várias abordagens têm sido estabelecidas para lidar com as inovações no nível organizacional, que devem ser administradas adequadamente como qualquer outro processo. A partir dessa demanda, adentrou-se o campo da gestão da inovação.

De acordo com Tidd e Bessant (2015, p. 76), "a gestão da inovação em empresas de tecnologia tem grande reputação no mercado". A inovação digital se dá, em geral, por meio de produtos de tecnológicos (smartphones, tablets, computadores etc.) e serviços de base tecnológica (portais de atendimento, aplicativos de compra e venda de produtos, transporte, alimentação, etc.) Ela tem ampla influência pública e afeta a vida diária de todos, promove o trabalho diário e reduz a carga de trabalho e os custos.

Segundo Zen et al. (2017, p. 880), "a gestão da inovação tornou-se uma disciplina na última década do século 19, trabalhando na fábrica da Thomas Edison". Devido a Edison, a imagem de um inventor solitário foi transformada em um processo de inovação encenado, executado por um grupo de inventores trabalhando em conjunto.

A gestão da inovação da empresa é encarregada de sistematizar o processo de inovação, determinando as etapas e procedimentos do processo de inovação, quais recursos humanos, materiais, financeiros e técnicos utilizar, e estabelecendo uma estrutura hierárquica e de tomada de decisão para implementar e produzir resultados (STEFANOVITZ; NAGANO, 2014, p. 470).

Porém, hoje, o processo de inovação não está mais relacionado apenas a uma área, como a da pesquisa e do desenvolvimento, ele passou por várias etapas, desde o

RC: 102333

Link de acesso:

https://www.nucleodoconhecimento.com.br/administracao/desenvolvimento-dosprocessos 
desenvolvimento do produto até a comercialização. Vários métodos foram desenvolvidos para padronizar esse processo e, na maioria dos casos, esses métodos podem ser vistos como variantes do funil de inovação, um termo popular criado para o método de funil de desenvolvimento de produto.

\subsection{NECESSIDADE DE INOVAÇÃO DEVIDO AO AVANÇO TECNOLÓGICO}

Vivemos em um mercado globalizado e somos hostis às empresas que não se adaptam às mudanças frequentes. Por sua vez, as organizações que desejam se manter vivas devem desenvolver estratégias inovadoras e diferenciadas para se adaptarem a essas mudanças. São quatro os principais fatores que geram demanda por inovação: progresso tecnológico, mudanças nos consumidores e em suas necessidades, competição acirrada e mudanças no ambiente de negócios.

Par Webber; Vanin e Severo:

Pode-se ver diferentes movimentos que mudam os avanços tecnológicos
recentes em diferentes mercados. Por exemplo, devido à introdução de
telefones inteligentes, o mercado de telefonia móvel está passando por
mudanças fundamentais. Os telefones inteligentes permitem que cada
consumidor carregue um "laptop" com eles a qualquer momento (WEBBER;
VANIN; SEVERO, 2016, p. 3380). Mérida; Hasenclever e Carvalho (2019) dizem que os telefones celulares não são mais apenas dispositivos para fazer chamadas, agora eles nos dão a possibilidade acessar a Internet, verificar e-mails, assistir a vídeos e jogar. Além disso, por meio de aplicativos que permitem fazer ligações gratuitas pela Internet, a conexão desses aparelhos à Internet desencadeou uma revolução no mercado de telefonia, o que gerou um boicote por parte das operadoras de telefonia.

A introdução desta nova tecnologia atinge também outros campos, criando tipos de negócios. A introdução de smartphones também criou novos mercados, como o setor de transporte urbano, composto por empresas como a Uber, e empresas de

RC: 102333

Link de acesso:

https://www.nucleodoconhecimento.com.br/administracao/desenvolvimento-dosprocessos 
comércio eletrônico, como a Alibaba, que possibilitam a conceção com mercados distantes, com produtos acessíveis, por meio da tecnologia.

\subsection{MODERNIZAÇÃO ORGANIZACIONAL}

Este texto apresenta alguns aspectos da modernização ou não competitividade da empresa, chamados de indicadores de: modernização; inovação e gestão de tecnologia; gestão de negócios e tecnologia da informação; características de empreendedores inovadores; ciclo de vida de tecnologia de pequenas e microempresas industriais; dimensões competitivas e de estrutura organizacional inovadora.

De acordo com Oliveira (2014, p. 89), uma empresa moderna, com foco em negócios e gestão empresarial, é boa em novas técnicas de gestão e tem um espírito cada vez mais inovador, aparecendo no sistema para encontrar alternativas de gestão e técnicas. Uma empresa com características modernas sempre valoriza o capital humano, deve compreender a modernização da organização, considerar a inovação, a gestão da tecnologia e aceitar as mudanças da indústria.

Conforme Silveira (2015, p. 255), as mudanças tecnológicas introduziram-se no processo de ajuste da estrutura industrial e afetaram o posicionamento competitivo das empresas na estrutura do setor e no mercado. A vantagem competitiva vem de oportunidades de inovação em produtos / mercados, apoiados pela integração de funções organizacionais.

Em conclusão, ao se analisar a situação geral da competitividade da economia nacional, pode-se observar a coexistência de organizações com diferentes níveis de modernidade, ou seja, existem organizações reconhecidamente eficientes que dividem o mesmo ambiente econômico com outras organizações menos desenvolvidas, que sobrevivem em setores não competitivos e que se encontram em um processo de superação das práticas de gestão tradicionais.

RC: 102333

Link de acesso:

https://www.nucleodoconhecimento.com.br/administracao/desenvolvimento-dosprocessos 


\subsection{COMPETIVIDADE ORGANIZACIONAL}

Atualmente, a competitividade de uma organização depende de sua capacidade de mudar e formular novos rumos estratégicos, pois processo de pensar e considerar novas ideias e soluções desempenha um papel importante na obtenção de uma vantagem competitiva.

As expectativas da organização são determinadas principalmente pela vontade de buscar o lucro e de viver de forma satisfatória em meio às incertezas inerentes ao negócio, e a busca pela competitividade é a razão de sua existência. No entanto, além de ter expectativas, as empresas também precisam ter a capacidade de traduzir as expectativas em realidade.

Essa capacidade está associada a fatores ou habilidades de expressão na região, e têm um impacto positivo no mercado, na produção e nas finanças. Ela está relacionada ao pessoal, aos métodos e capacidades de planejamento, a organização e controle, em um nível que permite que a empresa enfrente organizações concorrentes e, portanto, a competição.

Competitividade significa permanecer no mercado. O conceito de competitividade tem como premissa implícita o conflito e a competição, o que torna difícil sua compreensão adequada. A economia, pode ser tratada no nível nacional (representado pela competitividade macroeconômica) e no nível organizacional (o núcleo da competitividade microeconômica). Quando a favor do microplanejamento, o tratamento recai sobre as características da organização ou produto, relacionadas ao desempenho ou eficiência técnica do processo de produção e gestão.

RC: 102333

Link de acesso:

https://www.nucleodoconhecimento.com.br/administracao/desenvolvimento-dosprocessos 


\subsection{TREINAMENTO PARA OS COLABORADORES}

Entende-se que além de aprimorar competências e conhecimentos, a formação visa também aprimorar o desenvolvimento profissional dos colaboradores da organização no desempenho de suas funções. Acredita-se que o treinamento pode trazer grande retorno para profissionais e empresas, pois profissionais mais qualificados terão maior motivação na execução das tarefas e, portanto, a maior produtividade dos colaboradores efetivamente promoverá resultados organizacionais.

Para Lacombe (2017, p. 67), "o treinamento é um processo de assimilação cultural de curto prazo, que visa transferir ou recuperar conhecimentos, habilidades ou atitudes diretamente relacionadas à execução de tarefas ou otimização do trabalho".

Já para Marras (2017, p. 145), o treinamento é um processo educacional com foco no curto prazo, aplicado de forma sistemática e organizada, por meio do qual as pessoas desenvolvem conhecimentos, competências e habilidades de acordo com as metas estabelecidas.

O treinamento é uma experiência de aprendizagem que pode gerar uma mudança relativamente permanente para os indivíduos e melhorar sua capacidade de concluir o trabalho. O treinamento pode envolver mudanças em competências, princípios, comportamentos ou desempenhos, ou seja, pode transformar o conhecimento do funcionário, o estilo de trabalho, a atitude de trabalho ou a interação com colegas ou supervisores.

\section{MATERIAIS E MÉTODOS}

Pode-se pensar na metodologia científica como uma ferramenta de suma relevância, que reúne diversos meios que auxiliam na realização da pesquisa científica. Dessa forma, essa ferramenta foi utilizada para solucionar questões éticas e legais e ajudar a delinear o tema, ou, mais precisamente, auxiliou nas decisões, na escolha dos

RC: 102333

Link de acesso:

https://www.nucleodoconhecimento.com.br/administracao/desenvolvimento-dosprocessos 
meios e das questões a serem tratadas, para que o tema não fosse ampliado de forma inadequada (ALMEIDA, 2016).

\subsection{PROCEDIMENTOS METODOLÓGICOS}

No que diz respeito a escolha dos métodos e procedimentos utilizados na pesquisa, é importante ressaltar a importância da coerência do pesquisador com a forma de se estabelecer a construção do conhecimento e o que se pretende fazer. A metodologia que constitui um estudo nada mais é do que explicar o porquê de se coletar certos dados, quais dados são coletados, onde, quando e como você coleta esses dados e como analisá-los (FLEURY; WERLANG, 2016).

\subsubsection{QUANTO À NATUREZA}

O presente estudo foi elaborado no formato de uma pesquisa de natureza básica, na qual foi possível desenvolver novos conhecimentos que se mostraram extremamente úteis para a prosperidade dos estudos. De acordo com Martelli et al. (2020), a pesquisa de natureza básica tem como objetivo o desenvolvimento de novos conhecimentos para o emprego no avanço da ciência, e sem uma execução prévia a pesquisa envolve todos os interesses e verdades existentes.

\subsubsection{QUANTO AOS FINS}

Com relação aos fins, o estudo se caracteriza como uma pesquisa descritiva. Leão (2019, p. 78) afirma que a pesquisa descritiva visa descrever os principais aspectos de um fenômeno, população ou qualquer outra variável, assim como "observar, analisar e organizar os dados para que possam ser manipulados sem a interferência dos pesquisadores".

RC: 102333

Link de acesso:

https://www.nucleodoconhecimento.com.br/administracao/desenvolvimento-dosprocessos 


\subsubsection{QUANTO AOS MEIOS}

Este trabalho pautou-se em um estudo de caso, no qual foi possível visualizar de forma detalhada a solução para o problema em questão. Segundo Severino (2017), o estudo de caso tem como objetivo investigar questões empíricas. Ele utiliza uma metodologia de pesquisa com dados qualitativos, coletados a partir de eventos reais, com o objetivo de esclarecer, explorar ou apresentar acontecimentos atuais fincados em seu próprio contexto. Definindo-se por apresentar um conhecimento detalhado e exaustivo em seus estudos, fornecendo conhecimentos intrínsecos

Quanto aos meios, deu-se preferência a pesquisa bibliográfica, que se utiliza de publicações já existentes para o embasamento teórico, por meio livros, artigos, teses e dissertações que estejam ligados ao tema proposto. Segundo Estrela (2018), destaca-se que a pesquisa bibliográfica é construída a partir de material idealizado, residindo no fato de o investigador realizar uma cobertura sobre uma diversidade de fenômenos.

\subsection{CARACTERIZAÇÃO DA EMPRESA}

A empresa X foi fundada no ano de 1948, em São Paulo, e incialmente era uma loja voltada para a venda de bolsas. Ao decorrer do tempo, o fundador começou a investir em outros produtos e mudou o foco de sua loja para venda de roupas em varejo, voltada para o público feminino e para produtos acessíveis que possam atender o público de baixa renda. Desse modo, foi inaugurada a primeira ponta de estoque do Brasil.

Após o grande sucesso o nome inicial da loja foi substituído e ela passou a se chamar Empresa X. Incorporou a filosofia de oferecer às mulheres roupas de qualidade com preços acessíveis e passou a vender produtos de grandes fabricantes a preços competitivos com o mercado.

RC: 102333

Link de acesso:

https://www.nucleodoconhecimento.com.br/administracao/desenvolvimento-dosprocessos 
A Empresa $X$, independentemente de sua filial, se esforça para trazer um atendimento padrão para suas lojas. Cada loja contém cerca de 18 funcionários, que trabalham em busca de melhorar o atendimento e proporcionar serviços e produtos de qualidade.

Foi constatado que os principais clientes da loja são moradores da região, que se encontram na faixa de idade dos 18 aos 60 anos. Os principais concorrentes da Empresa X são: C\&A, Renner, Riachuelo, Forever 21, Zara, Loja do Queima e Asia Fashion.

\section{RESULTADOS E DISCUSSÕES}

Com base na análise de desempenho realizada na empresa $X$, por meio de entrevistas com os colaborares e supervisores organizacionais e de análises, chegou-se à conclusão de que a empresa vinha adotando métodos ineficazes de gestão de aquisições, e devido a isso não conseguiu alcançar resultados seguros em sua gestão referente a Tecnologia da Informação.

\subsection{GRÁFICO DAS ÁREAS CRÍTICAS}

De acordo com gráfico 1, a área de operações foi identificada como a área mais crítica da organização, demonstrando problemas de insuficiência de máquinas e equipamento, péssima qualidade de instalações de equipamentos e falta de segurança com relação aos equipamentos. Todos os pontos listados são fundamentais para que a empresa possa operar da melhor forma, sendo assim, é fundamental haja uma intervenção para correção desses problemas.

RC: 102333

Link de acesso:

https://www.nucleodoconhecimento.com.br/administracao/desenvolvimento-dosprocessos 
Gráfico 1 - Gráfico - Média - Desempenho por área funcional.

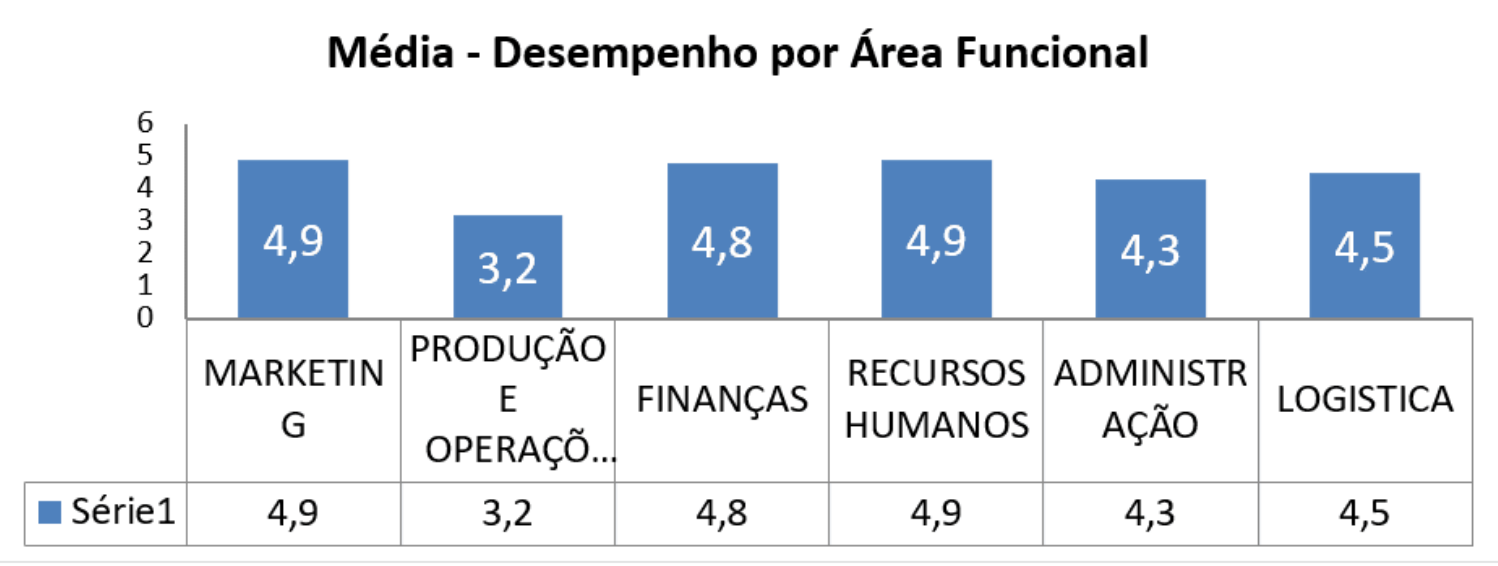

Fonte: Desenvolvido pelos autores, 2021.

Com base no gráfico 1 , pode-se ressaltar que a realização da medição de desempenho é algo fundamental para qualquer atividade. Por exemplo, ao tomarmos a decisão de praticar jogging, sentiremos a necessidade de comprar um relógio com um cronômetro e correr em uma pista demarcada para saber de que forma melhoramos nosso desempenho em termos de distância percorrida e tempo. O mesmo ocorre dentro de uma empresa. Por meio da medição do desempenho de cada área funcional é possível saber quais delas mostram um bom desempenho e quais necessitam de melhorias, e por isso a análise é recomendada.

\subsection{QUADRO DA ÁREA MAIS CRÍTICA}

No Quadro 1, pode-se observar de forma detalhada a performance da empresa no setor no que corresponde a sua área de operações, de modo a evidenciar o grau de avaliação da empresa.

Quadro 1 - Operações

\section{AREA FUNCIONAL OPERAÇÕES} NÍVEL OU GRAU DE AVALIAÇÃO

Ponto Ponto Ponto Ponto Ponto

RC: 102333

Link de acesso:

https://www.nucleodoconhecimento.com.br/administracao/desenvolvimento-dosprocessos 


\begin{tabular}{|c|c|c|c|c|c|c|}
\hline \multirow{2}{*}{\multicolumn{2}{|c|}{$\begin{array}{l}\text { A empresa possui controle de } \\
\text { matérias primas. }\end{array}$}} & \multirow[t]{2}{*}{$\begin{array}{l}\text { muito } \\
\text { forte } \\
5\end{array}$} & \multirow{2}{*}{$\begin{array}{l}\text { forte } \\
4 \\
x\end{array}$} & \multirow[t]{2}{*}{$\begin{array}{l}\text { médio } \\
3\end{array}$} & \multirow[t]{2}{*}{$\begin{array}{l}\text { fraco } \\
2\end{array}$} & \multirow[t]{2}{*}{$\begin{array}{l}\text { muito } \\
\text { fraco } \\
1\end{array}$} \\
\hline & & & & & & \\
\hline 2 & $\begin{array}{l}\text { A empresa tem capacidade } \\
\text { produtiva. }\end{array}$ & & $x$ & & & \\
\hline 3 & $\begin{array}{l}\text { A empresa tem máquinas e } \\
\text { equipamentos suficientes. }\end{array}$ & & & & $x$ & \\
\hline 4 & $\begin{array}{l}\text { A organização avalia eficiência e } \\
\text { produtividade. }\end{array}$ & $\mathrm{x}$ & & & & \\
\hline 5 & $\begin{array}{l}\text { A empresa apresenta modernização } \\
\text { dos equipamentos eletrônicos. }\end{array}$ & & & & $x$ & \\
\hline 6 & $\begin{array}{l}\text { A organização apresenta } \\
\text { flexibilização sobre a sua produção. }\end{array}$ & $\mathrm{x}$ & & & & \\
\hline 7 & $\begin{array}{l}\text { A empresa tem capacidade de } \\
\text { suporte com as maquinas com } \\
\text { defeitos }\end{array}$ & & & $x$ & & \\
\hline 8 & $\begin{array}{l}\text { Nível das instalações de } \\
\text { equipamentos. }\end{array}$ & & & & $x$ & \\
\hline 9 & $\begin{array}{l}\text { A empresa realiza inovação de } \\
\text { processo produtivo. }\end{array}$ & $x$ & & & & \\
\hline 10 & Nível de segurança no trabalho. & & & & $x$ & \\
\hline \multicolumn{2}{|c|}{ TOTAL $(\Sigma)$} & 15 & 8 & 3 & 6 & 0 \\
\hline \multicolumn{2}{|r|}{ MÉDIA POR GRAU (POR COLUNA) } & 1,5 & 0,8 & 0,3 & 0,6 & 0 \\
\hline \multicolumn{2}{|c|}{ DESEMPENHO DA ÁREA } & \multicolumn{5}{|l|}{3,2} \\
\hline
\end{tabular}

Fonte: Desenvolvido pelos autores, 2021

De acordo com o Quadro 1, a empresa demonstrou em seus indicadores alguns bons resultados, tais como: a avaliação de eficiência e produtividade da

RC: 102333

Link de acesso:

https://www.nucleodoconhecimento.com.br/administracao/desenvolvimento-dosprocessos 
organização, o controle de estoque e a organização apresentado pela empresa e a flexibilização sobre a sua produção. Todavia, também pôde-se observar alguns pontos médios e fracos, que retrataram algumas deficiências, como: a baixa disponibilidade de máquinas e equipamentos para os colaboradores, o baixo nível das instalações de equipamentos e o baixo nível de segurança com relação aos equipamentos. Devido a demanda por melhorias, surgem dispositivos cada vez mais modernos e fáceis de usar, o que facilitou muito a vida dos empresários. Eles conseguiram expandir e aumentar a produtividade de produtos e serviços, e até mesmo reduzir os custos de mão de obra.

Uma empresa organizada planeja seu crescimento, controla seu caixa e entende que para crescer precisa de investimentos, e esse investimento geralmente envolve a compra do equipamento. Por outro lado, um equipamento que não passa por manutenção regular somente mostrará sinais de que suas peças precisam ser substituídas quando todas as suas funções forem danificadas. Quando isso acontece, é quase impossível restaurar a máquina, e a empresa tem que substituí-la por uma nova. Como resultado, a frequência de troca de equipamento eventualmente se torna mais alta, já que a vida útil de uma máquina sem manutenção caí de 10 anos para 6 anos.

\subsection{QUADRO DAS AÇÕES INTERVENTIVAS}

As ações de intervenção são fundamentais porque a empresa deve estar atenta à necessidade de oferecer qualidade contínua em todos os seus processos, principalmente ao nível da qualidade do serviço ao cliente. É necessário que a empresa estabeleça uma relação de respeito e carinho com seus clientes e busque atendê-los da melhor forma. Os clientes só querem que a empresa realmente se preocupe em resolver seus problemas e lhes dê feedback e atenção para mostrar que realmente se preocupam com seus ativos humanos. Dessa maneira, foram inseridas as seguintes ações interventivas, de acordo com Quadro 2.

RC: 102333

Link de acesso:

https://www.nucleodoconhecimento.com.br/administracao/desenvolvimento-dosprocessos 
Quadro 2 - Ações Interventivas

\begin{tabular}{|c|c|c|c|c|}
\hline & Ações Interventivas & Cronologia & Duração & Custo \\
\hline 1 & $\begin{array}{l}\text { Desenvolver um mapeamento dos } \\
\text { processos de } \mathrm{TI}\end{array}$ & 01/09/2021 & 15 dias & $\begin{array}{l}\mathrm{R} \$ \\
1.000,00\end{array}$ \\
\hline 2 & $\begin{array}{l}\text { Estruturar um plano de cotação e compras } \\
\text { de materiais tecnológicos (totem de } \\
\text { autoatendimento, impressora de cartão } \\
\text { moderna e sistema interno de câmeras). }\end{array}$ & $15 / 09 / 2021$ & 15 dias & $\begin{array}{l}\mathrm{R} \$ \\
18.000,00\end{array}$ \\
\hline 3 & $\begin{array}{l}\text { Categorizar itens tecnológicos para } \\
\text { inserção no processo (totem de } \\
\text { autoatendimento, impressora de cartão } \\
\text { moderna e sistema interno de câmeras) }\end{array}$ & $30 / 09 / 2021$ & 15 dias & $\begin{array}{l}R \$ \\
2.000,00\end{array}$ \\
\hline 4 & $\begin{array}{l}\text { Treinar colaboradores para manusear } \\
\text { tecnológicas (totem de autoatendimento, } \\
\text { impressora de cartão moderna e sistema } \\
\text { interno de câmeras). }\end{array}$ & $15 / 10 / 2021$ & 15 dias & $\begin{array}{l}R \$ \\
2.500,00\end{array}$ \\
\hline 5 & $\begin{array}{l}\text { Implementação dos sistemas novos de } \\
\text { tecnologias }\end{array}$ & $31 / 10 / 2021$ & 15 dias & $\begin{array}{l}R \$ \\
2.000,00\end{array}$ \\
\hline 6 & $\begin{array}{l}\text { Realizar análise com indicadores sobre os } \\
\text { itens }\end{array}$ & $30 / 11 / 2021$ & 30 dias & $\begin{array}{l}\mathrm{R} \$ \\
1.000,00\end{array}$ \\
\hline & \multicolumn{3}{|l|}{ Total } & $\begin{array}{l}R \$ \\
26.500,00\end{array}$ \\
\hline
\end{tabular}

Fonte: Elaborado pelos autores, 2021

Conforme o Quadro 2, as ações interventivas utilizaram ferramenta 5W2H como metodologia principal. A ferramenta $5 \mathrm{~W} 2 \mathrm{H}$ apresenta uma metodologia muito simples e prática, podendo ser utilizada em diversas áreas da empresa. Em um primeiro momento, foi desenvolvido um mapeamento dos processos de $\mathrm{TI}$, com duração de 15 dias, pelo custo $R \$ 1.000,00$. Em seguida, foi realizada a cotação e a

RC: 102333

Link de acesso:

https://www.nucleodoconhecimento.com.br/administracao/desenvolvimento-dosprocessos 
compra dos itens, com duração de 15 dias e no valor de $R \$ 18.000,00$. A terceira etapa consistiu na categorização dos itens adquiridos. Essa etapa foi planejada para durar 15 dias, pelo valor de $\mathrm{R} \$ 2.000,00$. A quarta etapa do plano se referiu ao treinamento dos colaboradores, para que pudessem realizar o manuseio dos itens tecnológicos. Este período requereu 15 dias de treinamento, pelo valor $R \$ 2.500,00$.

$\mathrm{Na}$ quinta etapa foi realizada a implementação das ações, de modo que elas passassem a serem usadas no dia-dia dos atendimentos na empresa. Essa etapa teve foi planejada para durar de 15 dias, pelo valor $R \$ 2.000,00$. Na sexta etapa, realizou-se uma análise com indicadores para elaborar o balanço das ações inseridas na empresa. No total, todas estas ações interventivas tiveram um custo de $\mathrm{R} \$ 26.500,00$. Esperava-se que este conjunto de ações pudesse proporcionar maior produtividade na loja, ampliando o relacionamento com os clientes, otimizando os processos e aumentando o ticket médio.

\subsubsection{MAPEAMENTO DOS PROCESSOS DE TI}

Esta seção apresenta o mapeamento dos processos de $\mathrm{TI}$, demonstrado detalhadamente no plano de ação, de acordo com o Quadro 3.

Quadro 3 - Mapeamento dos processos de TI

Mapeamento dos processos de $\mathrm{TI}$

O que? Mapeamento dos processos de TI

Por quê? Realização de levantamento de informações na empresa

Onde? Empresa X

Quando? Primeira quinzena de setembro/2021

Quem? Setor de Tecnologia da Informação

Como? Mediante as informações levantadas na empresa

RC: 102333

Link de acesso:

https://www.nucleodoconhecimento.com.br/administracao/desenvolvimento-dosprocessos 


\section{Quanto? $\mathrm{R} \$ 1.000,00$}

Fonte: Elaborado pelos autores, 2021

Segundo o Quadro 3, a primeira etapa do ações interventivas consiste em realizar o mapeamento de processos, que é uma técnica que orienta o desenvolvimento da avaliação de processos existentes em um departamento de uma organização, fornecendo para empresa uma compreensão abrangente de todos os processos e membros da organização, para que se possa ver o estágio atual de funcionamento da organização. Essa reflexão muitas vezes melhora a dinâmica de desempenho das múltiplas tarefas realizadas e o desenvolvimento de cada processo.

\subsubsection{ESTRUTURAÇÃO DE UM PLANO DE COTAÇÃO E COMPRAS DE MATERIAIS TECNOLÓGICOS}

Como se pode observar no Quadro 4, nesta etapa foi estruturado um plano de cotação e compras de materiais tecnológicos.

Quadro 4 - Estruturação de um plano de cotação e compras de materiais tecnológicos.
Estruturação de um plano de cotação e compras de materiais tecnológicos
O que? Estruturação de um plano de cotação e compras de materiais tecnológicos

Por quê? Obtenção de maiores informações sobre a empresa

Onde? A empresa $X$

Quando? Segunda quinzena de setembro/2021

Quem? Setor de Compras / Setor de TI

Como? Mediante as informações levantadas na empresa

Quanto? $\mathrm{R} \$ 18.000,00$

Fonte: Elaborado pelos autores, 2021

RC: 102333

Link de acesso:

https://www.nucleodoconhecimento.com.br/administracao/desenvolvimento-dosprocessos 
De acordo com o Quadro 4, a segunda etapa de ações interventivas consistiu em verificar o orçamento, que incluí uma análise dos custos associados a cada etapa da execução do serviço, considerando o preço dos itens e a relação com a mão de obra. Esta etapa é muito importante, porque ajuda a organização a economizar muito dinheiro e evitar perdas futuras.

\subsubsection{CATEGORIZAÇÃO DE ITENS TECNOLÓGICOS PARA INSERÇÃO NO PROCESSO}

Apresenta-se no Quadro 5 o plano de categorização de itens tecnológicos para inserção no processo.

Quadro 5 - Categorização de itens tecnológicos para inserção no processo.

Categorização de itens tecnológicos para inserção no processo

O que? Categorização de itens tecnológicos para inserção no processo

Por quê? Obtenção de maiores informações sobre a empresa

Onde? A empresa $X$

Quando? Primeira quinzena de outubro/2021.

Quem? Setor de Compras / Setor de TI

Como? Mediante ao diagnóstico da empresa

Quanto? $\mathrm{R} \$ 2.000,00$

Fonte: Elaborado pelos autores, 2021

De acordo com o Quadro 5, os resultados da terceira etapa das ações interventivas afirmaram que a tecnologia trouxe melhorias substanciais nas atividades diárias do mundo corporativo. Cada vez mais os desenvolvimentos tecnológicos têm promovido uma melhora na execução de tarefas e garantido uma maior segurança das operações empresariais. Nesse contexto, a instalação de itens tecnológicos

RC: 102333

Link de acesso:

https://www.nucleodoconhecimento.com.br/administracao/desenvolvimento-dosprocessos 
como: totem de autoatendimento, impressora de cartão moderna e sistema interno de câmeras, foram de suma importância ao bom desempenho da empresa.

\subsubsection{TREINAMENTO DOS COLABORADORES PARA MANUSEAR TECNOLÓGICAS}

No Quadro 6, apresenta-se o plano de ação delimitado para treinamento dos colaboradores para manuseio de tecnológicas

Quadro 6 - Treinamento dos colaboradores para manusear tecnológicas.

\begin{tabular}{l|l|}
\hline Treinamento dos colaboradores para manuseio tecnológicas \\
\hline O que? & $\begin{array}{l}\text { Treinamento dos colaboradores para manusear } \\
\text { tecnológicas }\end{array}$ \\
\hline Por quê? & Obtenção de maiores informações sobre a empresa \\
\hline Onde? & A empresa X \\
\hline Quando? & Segunda quinzena de outubro/2021. \\
\hline Quem? & Setor de Recursos Humanos / Setor de $\mathrm{TI}$ \\
\hline Como? & Mediante ao diagnóstico da empresa \\
\hline Quanto? & $\mathrm{R} \$ 2.500,00$ \\
\hline
\end{tabular}

Fonte: Elaborado pelos autores, 2021

No Quadro 6, pode-se observar a quarta etapa das ações interventivas, que consistiu em realizar o treinamento dos colaboradores, visando um trabalho de mais qualidade, melhorias no retorno para a empresa e feedback positivo para os colaboradores. Desta forma, o entusiasmo dos funcionários aumentou e eles obtiveram bons resultados na execução de seu trabalho.

RC: 102333

Link de acesso:

https://www.nucleodoconhecimento.com.br/administracao/desenvolvimento-dosprocessos 


\subsubsection{IMPLEMENTAÇÃO DOS SISTEMAS NOVOS DE TECNOLOGIAS}

Esta seção apresenta a implementação dos sistemas novos de tecnologias, como pode ser observado no quadro 7 .

Quadro 7 - Implementação dos sistemas novos de tecnologias.

Implementação dos novos sistemas de tecnologias

O que? Implementação dos novos sistemas de tecnologias

Por quê? Obtenção de maiores informações sobre a empresa

Onde? A empresa $\mathrm{X}$

Quando? Primeira quinzena de novembro/2021

Quem? Setor de TI

Como? Mediante ao diagnóstico da empresa

Quanto? R\$2.000,00

Fonte: Elaborado pelos autores, 2021

De acordo com o quadro 7, a quinta etapa do ações interventivas consistiu em realizar a implementação de todos os itens comprados que passaram pelo treinamento com os colaboradores. Inicialmente, indicou-se a realização de um teste para identificar qualquer variável que poderia implicar em erros, todavia, tratou-se de uma etapa que concretizou todo trabalho realizado, gerando grandes oportunidades, otimizando os processos e aumentando efetivamente a produtividade de todos que faziam parte daquela empresa.

\subsubsection{REALIZAÇÃO DE UMA ANÁLISE SOBRE OS KPI'S}

Esta última etapa é evidencia o plano de realização de análise de KPI'S, conforme apresentado no quadro 8.

RC: 102333

Link de acesso:

https://www.nucleodoconhecimento.com.br/administracao/desenvolvimento-dosprocessos 
Quadro 8 - Realização de uma análise sobre os KPI's.

\begin{tabular}{|c|c|}
\hline \multicolumn{2}{|c|}{ Realização de uma análise sobre os KPI's } \\
\hline O que? & Realização de uma análise sobre os KPI's \\
\hline Por quê? & $\begin{array}{l}\text { Obtenção de maiores informações sobre a } \\
\text { empresa }\end{array}$ \\
\hline Onde? & A empresa $X$ \\
\hline Quando? & Segunda quinzena de novembro/2021 \\
\hline Quem? & Setor de TI \\
\hline Como? & Mediante ao diagnóstico da empresa \\
\hline Quanto? & $\mathrm{R} \$ 1.000,00$ \\
\hline
\end{tabular}

Fonte: Elaborado pelos autores, 2021

O monitoramento sistemático das metas estabelecidas foi realizado por meio dos indicadores, que foram usados para medir o desempenho das atividades e processos da empresa. A maior vantagem de usar KPls foi a transformação dos números individuais em conhecimento de negócios. Com esses dados, os gestores puderam fazer previsões e descobrir problemas no andamento das atividades, para que, assim, pudessem ajustar suas estratégias se necessário.

\section{CONSIDERAÇÕES FINAIS}

Diante das informações levantadas no diagnóstico organizacional do presente trabalho, foi identificado o problema do estudo de caso da empresa X. Por meio de coleta de dados no departamento de operações da organização, foi comprovado a incidência e não conformidades. A ficha de avaliação das áreas mais críticas da empresa apresenta os pontos a serem melhorados, como a área tecnologia e informação (TI).

Esta pesquisa tem o objetivo de apresentar melhorias de acordo com os resultados operacionais, por meio da otimização do desenvolvimento de processos de

RC: 102333

Link de acesso:

https://www.nucleodoconhecimento.com.br/administracao/desenvolvimento-dosprocessos 
tecnologia e informação (TI). Desse modo, foi desenvolvido um plano de ação com a finalidade de melhoria e modernização de equipamentos tecnológicos para suporte e produtividade organizacional, de modo a auxiliar na melhora de seu ambiente de negócio e estimular a competitividade com outras empresas.

Respondendo à problemática do trabalho: como o desenvolvimento dos processos de Tecnologia e Informação (TI) pode auxiliar na modernização de equipamento tecnológico para suporte e produtividade organizacional? verificou-se que o estudo de caso atingiu seus propósitos com a elaboração de uma proposta que inseriu as ações interventivas na empresa. Teve-se como objetivo: desenvolver um mapeamento dos processos de $\mathrm{Tl}$, estruturar um plano de cotação e compras de materiais tecnológicos, categorizar itens tecnológicos para inserção no processo, treinar colaboradores para manusearem tecnologias, implementar novos sistemas de tecnologias e realizar uma análise com indicadores sobre os itens. Estas ações puderam otimizar e modernizar os processos e elevar a competição no seu nicho de mercado, e por isso se apresentaram como um fator fundamental à produtividade da empresa.

A aplicação desse método segue um padrão de entrevistas com gestores e colaboradores que expressaram a falta de uma forma de promover o trabalho para atrair mais clientes. Portanto, a fim de encontrar estratégias e soluções viáveis com base nas necessidades atuais da organização e na realidade das operações de $\mathrm{TI}$, recomendou-se utilizar as ferramentas $5 \mathrm{~W} 2 \mathrm{H}$ como método de melhoria contínua, e implementar planos de ação para obtenção de soluções. De modo geral, pode-se dizer o objetivo do trabalho foi alcançado com êxito, pois, com base nas pesquisas e análises, foi desenvolvido um artigo para auxiliar na melhora dos resultados operacionais por meio do desenvolvimento dos processos de Tecnologia e Informação ( $\mathrm{Tl})$, com foco na melhoria e modernização de equipamentos tecnológicos para suporte e produtividade organizacional.

RC: 102333

Link de acesso:

https://www.nucleodoconhecimento.com.br/administracao/desenvolvimento-dosprocessos 
Em conclusão, é recomendável que as organizações mantenham seus processos atualizados por meio da inclusão de novas tecnologias, para que se possa manter relacionamentos de longo prazo com seus clientes.

\section{REFERÊNCIAS}

ALMEIDA, N.G.N.de. A importância da metodologia científica através do projeto de pesquisa para a construção da monografia. Revista de Biblioteconomia e Ciência da Informação, v.2, n. 1, p. 57-66, jan./jun., 2016.

ANA, W.P.S.; LEMOS, G.C. Metodologia Científica: a pesquisa qualitativa nas visões de Lüdke e André. Revista Eletrônica Científica Ensino Interdisciplinar, v. 4, n. 12, p. 531-541, 2018.

BATISTA, E. de O. Sistemas de informação. São Paulo: Saraiva Educação SA, 2017.

ESTRELA, C. Metodologia científica: ciência, ensino, pesquisa. Porto Alegre: Artes Médicas, 2018.

FLEURY, M.T.L; WERLANG, S.R. Pesquisa aplicada: conceitos e abordagens. São Paulo: Anuário de Pesquisa FGV Pesquisa, 2016.

GOMES, C.F.S.; RIBEIRO, P.C.C. Gestão da cadeia de suprimentos integrada à tecnologia da informação. Rio de Janeiro: Editora Senac Rio, 2020.

LACOMBE, F.J.M. Recursos humanos. São Paulo: Saraiva Educação SA, 2017.

LEÃO, L.M. Metodologia do estudo e pesquisa: facilitando a vida dos estudantes, professores e pesquisadores. São Paulo: Editora Vozes, 2019.

MARRAS, J.P. Administração de recursos humanos. São Paulo: Saraiva Educação SA, 2017.

RC: 102333

Link de acesso:

https://www.nucleodoconhecimento.com.br/administracao/desenvolvimento-dosprocessos 
MARTELLI, A. et al. Análise de metodologias para execução de pesquisas tecnológicas. Brazilian Applied Science Review, v. 4, n. 2, p. 468-477, 2020.

MÉRIDA, S.M.A.; HASENCLEVER, L.; CARVALHO, M.M. Reflexos das inovações tecnológicas sobre o emprego: uma revisão da literatura. Brazilian Journal of Development, v. 5, n. 11, p. 26735-26761, 2019.

OLIVEIRA, L.L. A cultura como campo de inovações organizacionais. Interseções: Revista de Estudos Interdisciplinares, v. 16, n. 1, p.90-110, 2014.

SALLES, A.C. et al. Tecnologia da informação verde: Um estudo sobre sua adoção nas organizações. Revista de Administração Contemporânea, v. 20, p. 41-63, 2016.

SCHNEIDER, R.M. et al. A influência de fatores organizacionais na gestão de projetos de tecnologia da informação (TI). Revista Gestão \& Tecnologia, v. 16, n. 1, p. 157-183, 2016.

SEVERINO, A.J. Metodologia do trabalho científico. São Paulo: Cortez Editora, 2017.

SILVEIRA, M.L. Modernização contemporânea e nova constituição dos circuitos da economia urbana. GEOUSP Espaço e Tempo (Online), v. 19, n. 2, p. 245-261, 2015.

SIQUEIRA, L.D.; CRISPIM, S.F. Alinhamento dos projetos de TI aos modelos de negócio das organizações. Gestão \& Produção, v. 21, p. 621-634, 2014.

STEFANOVITZ, J.P.; NAGANO, M.S. Gestão da inovação de produto: proposição de um modelo integrado. Production, v. 24, p. 462-476, 2014.

TIDD, J.; BESSANT, J. Gestão da inovação. $5^{a}$ ed. Porto Alegre: Bookman Editora, 2015.

RC: 102333

Link de acesso:

https://www.nucleodoconhecimento.com.br/administracao/desenvolvimento-dosprocessos 
WEBBER, C.; VANIN, M.S.; SEVERO, E.A. O processo de inovação no varejo. Revista GEINTEC - Gestão, Inovação e Tecnologias, v. 6, n. 3, p. 3377-3391, 2016.

ZEN, A.C. et al. Rota da inovação: uma proposta de metodologia de gestão da inovação. Revista de administração contemporânea, v. 21, p. 875-892, 2017.

Enviado: Outubro, 2021.

Aprovado: Novembro, 2021.

RC: 102333

Link de acesso:

https://www.nucleodoconhecimento.com.br/administracao/desenvolvimento-dosprocessos 